os uteri. Within the liquor amnii I distinctlymade out a large loop of pulsating umbilical cord. An examination between the pains discovered the vertex presenting within the os. Havingunsucessfully attempted to return the prolapsed funis with the membranes intact, I determined to try manual reposition more fully. Rupturing the membranes, I passed my hand into the vagina, and pushing back the vertex from the os, gradually returned the whole length of cord along the side of the head into the hollow of the nape of the neck, lying above the pubes of the mother, and retaining it there until, a pain coming, the vertex was forced down upon the now almost dilated os. Keeping my hand still within the vagina for some successive pains, and finding no further return of the prolapse, I left the remainder of the labour to nature, when in due course a living full-sized child was born, the cord following the birth of the head and shoulders. Both mother and child are doing well.

This same patient had been attended by me in July, 1883, with her second child. A long loop of the umbilical cord was then prolapsed, but upon my first examination the head was so low down that no reposition was effectual, the result being the birth of a stillborn infant. In her third confinement she was attended by one of my medical confrères, and again the cord was prolapsed and not returnable, with the result of another stillborn child. Her first and fourth labours, I gather from her, were natural, though difficult.

An interesting feature in this case, apart from the success of the artificial reposition of the prolapsed funis (which reposition, by the way, was exceedingly easily effected), is that three out of five pregnancies resulted in prolapse of the cord, which in each case was of unusual length, and not passed round the neck of the infant.

Somersham, Hants.

\section{THE VALUE OF BELLADONNA AND HYOSCYAMUS IN DYSMENORRHCEA.}

BY JAMES SHAw, M.B. GLAS.

DuRING the last year I have had occasion to treat several cases of that form of dysmenorrhcea vaguely and variously designated neuralgic or spasmodic, and occurring in young girls, whom it was of course very undesirable to examine. One of these cases was of marked severity, and, as it had continued for about a year, there was considerable nervous prostration. Morphia was the only drug that at all mitigated the suffering, but in consequence of its administration the patient was wretchedly troubled with headache and constipation and so I was forced to abandon its use. I therefore prescribed the following mix ture, one ounce to be taken three times a day, and it acted like a charm: val. belladonna, nine minims; val. hyoscyami, two scruples; syr. aurantii two drachms; water, six ounces. The epoch has now been robbed of its terrors for her. Writing the other day from Germany to her mother, she says the last six months are the only happy ones she has known since the function was established. In the other four cases there was likewise considerable suffering, and in these also complete relief was afforded. I prescribe it to be begun a day before the period is expected, and continued while the pain requires it. The valoids I employ are those manufactured by Messrs. Burroughs, Wellcome, and Co., and for obtaining the characteristic actions of the drugs I know of no preparations that equal them. The old-fashioned tincture, though perhaps a trifle more elegant, is at once feeble, expensive, and unreliable. In the majority of them the spirit is the active ingredient.

Sheerness-on-Sea.

ENLARGEMENT OF THE General INFIrimary, LEEDs. - The contemplated extension of this institution is about to be carried out, at an estimated cost of $£ 30,000$. An impetus has been given to provide the improvements and enlargement required by a donation from Colonel North of $£ 5000$ towards the erection of the building. Of late, subscriptions have rapidly come in, and a sum of orer $£ 30,000$ has been received. The board of management, in conjunction with the Faculty of the Infirmary, are maturing their plans, which will comprise a children's ward, isolation wards, improved out-patients' rooms, a casualty ward, and new accommodation for the increasing work of the pathological department.

\section{A 嗮证rox}

\author{
HOSPITAL PRACTICE, \\ BRITISH AND FOREIGN.
}

Nulla autem est alia pro certo noscendi via, nisi quamplurimas et morborum et dissectionum historias, tum aliorum tum proprias collectas habere, et inter se comparare.-Morgagni De Sed. et Caus. Morb., lib. iv. Procemium.

\section{ST. THOMAS'S HOSPITAL.}

THREE CASES OF POISONING (RED OXIDE OF MERCURY, CORROSIVE SUBLIMATE, AND DINITROTOLUENE); RECOVERY ; REMARKS.

(Under the care of Dr. ORD.)

AMongsT the other duties of the house physician at a large hospital is usually comprised the attendance on casualty cases, including those of poisoning by many and varied substances. There are few occasions in practice in which more depends on skill in rapid diagnosis, which, combined with a good knowledge of toxicology and prompt action, will often eventuate in the saving of life. The annexed cases are examples of such, where severe symptoms followed the swallowing of red oxide of mercury, corrosive sublimate, and of dinitrotoluene. In the two former the symptoms, though of a serious character, present little worthy of comment, but the third deserves special attention, as the symptoms produced by this compound are almost unknown. For the subjoined notes and remarks we are indebted to Mr. H. J. Macevoy, B.Sc., late house physician.

CASE 1. Poisoning by red oxide of mercury; recovery.F. W. R , aged fifty-one; tailor. Admitted on July 8th, 1887; discharged July 20th. He has enjoyed good health, but drinks a good deal. Is of a reticent disposition. It appears that shortly after coming home at midnight on July 7 th, being somewhat drunk (according to the wife's account), he swallowed the contents of a small packet which he took out of his pocket. An emetic was administered without effect, and he was brought to the hospital in a cab, being apparently unable to walk.

On admission at 2 A.M., the man was in an unconscious condition, and vomiting. Pupils of average size, equal, and inactive to light. Face and hands cold and bathed in sweat. Pulse weak, not abnormally rapid. There were traces of a reddish powder on his beard, chin, and shirt resembling that found in a small packet (referred to above) brought up by a policeman. Does not answer questions put to him or put out his tongue, but keeps his teeth clenched. There is otherwise general muscular relaxation, and his evacuations are passed under him. The stomach was washed out with the stomach-pump. The vomit consisted of a watery fluid containing mucus, and holding a red powder in suspension; no blood. The red powder, subsequently examined by Dr. Bernays, turned out to be red oxide of mercury, of which the patient swallowed about a teaspoonful.

July 8th.-11 A.M. : The patient was ordered milk, limewater, and eggs, beaten up, to be taken frequently in small quantities, but has kept very little down (vomit contains no powder or blood). He still takes no notice of questions put to him, but his pupils now act to light. Bowels have been opened twice, the first motion consisting of loose frecal matter with mucus; the second motion is fluid and greenish, contains very little fæecal matter, but mucus and streaks of blood. - 4 P.II. : Patient has been conscious for the last two hours; apparently cannot protrude his tongue beyond his teeth. He complains of pain in the epigastrium and tenderness, and also of cramps in the legs. On examination the abdomen is rigid in the upper part, and slightly distended. Pulse regular, fair.

9th.-Patient is quiet, and feels better. Still occasional vomiting and diarrhoea, and the abdomen is rigid in the epigastric region and tender. No particular tenderness of gums; no salivation. He gradually improved after this, the romiting and diarrhoea ceased, and he left the hospital quite well.

CASE 2. Poisoning by corrasire sublimate; recovery.W. $\mathrm{B}-$, aged forty-nine; surgical instrument maker Admitted Aug. 31st; discharged Sept. 7th, 1887. Has had no serious illness, but suffered for about six years from 